\title{
Predictors of improvement in semen parameters after varicocelectomy for male subfertility: A prospective study
}

\author{
Waleed Shabana, MD; Mohamed Teleb, MD; Tamer Dawod, MD; Ehab Elsayed, MD; Esam Desoky, MD; \\ Ashraf Shahin, MD; Mahmoud Eladl, MD; Waleed Sorour, MD
}

Faculty of Medicine, Zagazig University, Egypt

Cite as: Can Urol Assoc J 2015;(9-10):E579-82. http://dx.doi.org/10.5489/cuai.2808

Published online September 9, 2015.

\section{Abstract}

Introduction: We aim to predict results of varicocelectomy on sperm density and progressive motility using preoperative clinical, laboratory and radiological data and to propose cut-off values for significant parameters.

Methods: This prospective study was carried out between July 2011 and June 2014. We included 123 patients in our study. They were diagnosed with primary infertility with varicocele, were scheduled for varicocelectomy, and completed their follow-up. We excluded patients with azoospermia, total necrospermia, recurrent varicocele, and pituitary hormonal abnormalities. Varicocele was diagnosed and graded by physical examination and colour Doppler ultrasound. Semen analyses were completed preoperatively and 6 months postoperatively. Microscopic subinguinal varicocelectomy was done in all cases. Patient demographics, pre- and postoperative clinical data (varicocele grade and semen parameters) were statistically analyzed.

Results: The mean \pm standard deviation of age, body mass index, and subfertility duration was $28.3 \pm 7.4$ years, $29.1 \pm 2.7 \mathrm{~kg} / \mathrm{m}^{2}$, and $21.9 \pm 7.1$ months, respectively. About $53 \%$ of our patients $(n=66)$ had bilateral varicocele, and unilateral disease was found in the other 57 (46.3\%) cases. Varicocele grade I was diagnosed in 42 (34.1\%) patients, while the other 81 (65.9\%) patients had grade II or III. Higher grades of varicocele, preoperative total testosterone level, sperm density, and progressive motility had a statistically significant impact on the outcome of varicocelectomy in univariate testing. Multivariate logistic analysis revealed that grade of preoperative varicocele (95\% confidence interval $[\mathrm{Cl}] 5.6-6.3, p=0.007)$ and sperm density (95\% Cl 2.7-1.6, $p=0.0035)$, and progressive motility $(95 \% \mathrm{Cl} 1.1-2.3, p=0.0123)$ are independent predictors of semen parameters improvement after varicocelectomy.

Conclusion: The grade of the varicocele, sperm density, and progressive motility are major predictors of outcome in varicocelectomy. Cut-off values of $>8$ million $/ \mathrm{mL}$ and $>18 \%$ for sperm density and progressive motility, respectively, in men with varicocele grade II or III, indicate a successful outcome.

\section{Introduction}

Varicocele is an abnormal enlargement and tortuosity of the pampiniform plexus of veins in the spermatic cord. It is the most common identifiable cause of male subfertility, with an estimated prevalence of $15 \%$ in the general male population and up to $40 \%$ in subfertile men. ${ }^{1}$ One of the theories of the varicocele influence on spermatogenesis is the resultant venous blood stagnation in the testis that increases oxidative stress and hinders spermatogenesis through a thermal effect. ${ }^{2}$ Varicocelectomy is by far the most common procedure to treat male subfertility in patients with clinical varicocele. It reduces intratesticular temperature to the normal range. ${ }^{3}$ Hence, semen parameters not uncommonly show significant improvement following varicocele ligation. There are many approaches for varicocelectomy..$^{4-6}$ Initially open surgical approach was the standard, but now there are alternative approaches, such as embolization and laparoscopy.,

The effect of varicocelectomy on semen analysis is controversial. Many articles report favourable outcomes, ${ }^{9-11}$ and others do not. ${ }^{12-14}$ Some authors noted an increase of total motile sperm count by more than $50 \%$ and spontaneous pregnancy rate of $37 \%$ achieved after varicocelectomy. ${ }^{15}$ Many authors tried to define preoperative parameters as patient age, obesity, and semen parameters to help predict varicocelectomy outcome. ${ }^{16-19}$ There is no literature regarding defined cut-off values for parameters that can predict a successful outcome of varicocelectomy on semen analysis. We aim to predict results of varicocelectomy on sperm density and progressive motility using preoperative clinical, laboratory and radiological data and to propose cut-off values for significant parameters. 
Shabana et al.

\section{Methods}

This prospective, non-controlled, observational study was carried out between July 2011 and June 2014, and included patient candidates for varicocelectomy with at least one abnormal semen parameter. Local ethics committee approval was obtained as was informed consent from every patient. Physical examination was done in both erect and supine positions. All patients underwent scrotal colour Doppler ultrasound during rest and Valsalva maneuver. The largest vein diameter and reversal blood flow of pampiniform plexus of veins were measured. According to physical examination, the varicocele was graded as grade I and II or III. Beside routine laboratory investigations, serum follicular-stimulating hormone ( $\mathrm{FSH}$ ), luteinizing hormone (LH), and total testosterone levels were measured. Patients with azoospermia, total necrospermia, recurrent varicocele, and pituitary hormonal abnormalities (such as high LH, FSH denoting primary testicular failure) were excluded from the study. In all patients, subinguinal microscopic varicocelectomy was done by the same surgeon who tried to preserve lymphatic vessels, testicular and vasal arteries in every case. The testis was delivered through the incision to facilitate ligation of external spermatic and gubernacular veins. Semen analysis was done (according to World Health Organization criteria 2010) preoperatively and 6 months postoperatively. Patients were declared responders if an improvement (to the normal value) occurred in at least one of the previous abnormal semen parameters.

\section{End points}

Our primary end point was determination of any significant predictors of varicocelectomy effect on sperm density and motility. The secondary end point was identification of proposed cut-off values of significant factors.

\section{Statistical analysis}

Univariate analysis was done using the unpaired student t-test and chi square test when appropriate. Multivariate logistic regression analysis and receiver operator characteristic (ROC) curves were plotted to outline the suggested cut-off values for significant parameters. Measurements were automatically calculated using Medcalc software.

\section{Results}

Of the 137 patients enrolled in this study, 123 patients completed the follow-up period for 6 months postoperatively. The mean \pm standard deviation of age, body mass index (BMI), and subfertility duration was $28.3 \pm 7.4$ years, $29.1 \pm 2.7 \mathrm{~kg} / \mathrm{m}^{2}$ and $21.9 \pm 7.1$ months, respectively. In total, 66 patients $(53.6 \%$ ) had bilateral varicocele, and unilateral disease was found in the other 57 (46.3\%) cases. Varicocele grade I was diagnosed in $42(34.1 \%)$ patients, while the other 81 (65.9\%) patients had grade II or III. Minor complications were noted postoperatively; these included testicular pain in $4(3.2 \%)$, edema in $6(4.8 \%)$, and hydrocele in $2(1.6 \%)$ patients. Improvement of sperm density and/ or progressive motility was noted in 87 patients $(70.7 \%)$. Six months after varicocelectomy, there were statistically significant increases in the mean total testosterone level, sperm density, and progressive motility. Postoperative FSH and $\mathrm{LH}$ levels did not significantly differ from preoperative ones (Table 1). Most patients with preoperative higher grades of varicoceles had significantly improved semen parameters after varicocelectomy. The results of the univariate analysis demonstrated that grade II or III varicoceles, preoperative total testosterone level, sperm density and progressive motility had affected the outcome of varicocelectomy (these results were statistically significant) (Table 2 , Table 3 ). ROC curve analysis proposed 8 million/mL and $18 \%$ as cut-off values for the preoperative sperm density and progressive motility, respectively (Fig. 1).

\section{Discussion}

Varicocele is the most common correctable cause of male subfertility. The incidence of varicocele in the general population is about $15 \%$ and contributes to at least one-third of male factor infertility. ${ }^{5}$ Varicocelectomy is a cost-effective treatment for infertility, with microsurgical subinguinal or inguinal as the best techniques. ${ }^{6}$ The beneficiary effect of varicocelectomy on the improvement of semen parameters has been extensively studied. ${ }^{15}$ However, these trials have not achieved a consistent conclusion due to the heterogeneity of inclusion criteria and variability of treatment methods.

In a study on 133 patients, sperm concentration, morphology, and motility improved in $42 \%, 57 \%$ and $29 \%$ of patients, respectively. ${ }^{16}$ In their meta-analysis of 22 articles studying varicocelectomy outcome on semen parameters, Belzile and colleagues recorded that the mean increase of sperm concentration was $12.3 \times 10^{6} / \mathrm{mL}(p<0.0001)$, while the mean improvement of motility was $9.7 \%(p=0.003) .{ }^{15}$

\begin{tabular}{lccc}
\hline \multicolumn{3}{l}{ Table 1. Pre- and postoperative laboratory measurements } \\
\hline Parameter & Preoperative & Postoperative & $p$ value \\
\hline $\begin{array}{l}\text { Mean sperm density } \\
\text { (million/mL) }\end{array}$ & $6.9 \pm 2.5$ & $17.3 \pm 4.8$ & $<0.0001$ \\
$\begin{array}{l}\text { Mean sperm } \\
\text { progressive motility (\%) }\end{array}$ & $9.3 \pm 2.8$ & $34.6 \pm 8.3$ & $<0.0001$ \\
FSH (mU/mL) & $7.4 \pm 1.6$ & $7.1 \pm 1.3$ & 0.1078 \\
LH (mU/mL) & $6.1 \pm 1.2$ & $5.9 \pm 1.1$ & 0.1743 \\
$\begin{array}{l}\text { Total testosterone } \\
\text { (ng/dL) }\end{array}$ & $385.6 \pm 41.3$ & $447.2 \pm 50.4$ & $<0.0001$ \\
\hline FSH: follicle-stimulating hormone; LH: luteinizing hormone. & &
\end{tabular}




\begin{tabular}{|c|c|c|c|}
\hline Probable predictor & Responders $(n=87$ ) & Non-responders $(n=36)$ & $p$ value \\
\hline Mean age (years) & $29.6 \pm 5.2$ & $31.3 \pm 4.7$ & 0.0926 \\
\hline Mean BMI (kg/m²) & $28.9 \pm 1.8$ & $29.3 \pm 1.9$ & 0.2721 \\
\hline Mean subfertility duration (months) & $21.6 \pm 7.2$ & $22.3 \pm 6.8$ & 0.6191 \\
\hline $\begin{array}{l}\text { Varicocele laterality } \\
\text { Bilateral } \\
\text { Unilateral }\end{array}$ & $\begin{array}{l}47(54 \%) \\
40(46 \%)\end{array}$ & $\begin{array}{l}19(52.8 \%) \\
17(47.2 \%)\end{array}$ & 0.942 \\
\hline $\begin{array}{l}\text { Varicocele grade: } \\
\text { Grade I } \\
\text { Grade II \& III }\end{array}$ & $\begin{array}{l}16(18.4 \%) \\
71(81.6 \%)\end{array}$ & $\begin{array}{l}26(72.2 \%) \\
10(27.8 \%)\end{array}$ & $<0.0001$ \\
\hline Mean preoperative sperm density (million/mL) & $10.57 \pm 1.66$ & $6.00 \pm 1.82$ & $<0.0001$ \\
\hline $\begin{array}{l}\text { Mean preoperative Sperm progressive } \\
\text { motility (\%) }\end{array}$ & $21.59 \pm 4.46$ & $18.39 \pm 5.08$ & 0.0007 \\
\hline $\mathrm{FSH}(\mathrm{mU} / \mathrm{mL})$ & $7.4 \pm 1.5$ & $7.9 \pm 1.3$ & 0.0833 \\
\hline $\mathrm{LH}(\mathrm{mU} / \mathrm{mL})$ & $5.9 \pm 0.8$ & $6.2 \pm 0.7$ & 0.0523 \\
\hline Total testosterone (ng/dL) & $394.06 \pm 24.88$ & $410.44 \pm 42.71$ & 0.0089 \\
\hline
\end{tabular}

BMI: body mass index; FSH: follicle-stimulating hormone; LH: luteinizing hormone.

In the present study, we tested various preoperative patient demographic, clinical and laboratory parameters to predict varicocelectomy results on semen analysis. The statistically significant increase in sperm density and progressive motility had a mean of $10.4 \times 10^{6}$ and $25.4 \%$, respectively. Many reports denied any relation between age at varicocelectomy and results of semen analysis or pregnancy rates. ${ }^{16,17}$

Hsiao and colleagues found that microsurgical varicocelectomy resulted in substantial changes in sperm concentration and sperm count in all studied groups, especially in men aged between 40 and 60 years. ${ }^{18}$ Also in this study we noted no effect of patient age on the degree of improvement in postoperative semen parameters. Choi and colleagues noted that lower age of the patient at the time of varicocelectomy was correlated to enhancement of sperm motility. ${ }^{19}$

The effect of obesity on male subfertility has been documented. Handel and colleagues reported a negative association between $\mathrm{BMI}$ and occurrence of varicocele. ${ }^{20} \mathrm{Hammoud}$ and colleagues addressed the correlation between low sperm concentration and obesity. ${ }^{21}$ Our study confirmed that lower $\mathrm{BMI}$ is an insignificant parameter for improvement of semen parameters after varicocelectomy. These results were also supported by Pham and colleagues, who stated that varicocelectomy for men with clinically palpable varicoceles has a significant chance of improving semen parameters regardless of preoperative BMI. ${ }^{22}$ With the exclusion of cases of high LH or FSH denoting primary tes- ticular failure from our study, we found that the duration of infertility and preoperative $\mathrm{LH}$ and FSH levels did not affect the impact of the varicocelectomy on postoperative semen analysis. Total testosterone level increased significantly after varicocelectomy and the improvement in semen parameters was better in those patients with preoperative levels under $400 \mathrm{ng} / \mathrm{dL}$. These results concur with those by Hsiao and colleagues, ${ }^{18}$ while Kondo and colleagues concluded that low serum FSH and high testosterone significantly predicted improvements in semen parameters. ${ }^{23}$ In a retrospective study of 202 patients, Rodriguez and colleagues did not find any significant predictive factors for improvement of the seminal fluid parameters. ${ }^{24}$

Many researchers have suggested that the clinical degree of varicoceles is associated with a response to the varicocelectomy and patients with higher varicocele grades had greater improvements in seminogram. ${ }^{16,25}$ Jonathan and colleagues noted that sperm count and motility improved significantly post-varicocelectomy in men with a vein diameter of more than $3 \mathrm{~mm}$, while those with veins smaller than $3 \mathrm{~mm}$ showed insignificant changes in seminogram. ${ }^{26}$ This was similarly noted by Jarow and colleagues. They found that seminogram parameters improved in men with varicoceles detected by ultrasound and proposed the same cut-off value of $3 \mathrm{~mm} .{ }^{27}$ Our results were similar to these articles; moderate or severe varicoceles ( $>3 \mathrm{~mm}$ vein diameter) were associated with better semen analysis outcome.

\begin{tabular}{|c|c|c|c|c|c|}
\hline Variable & OR & $95 \% \mathrm{Cl}$ & Coefficient & SE & $p$ value \\
\hline Varicocele grade & 5.9907 & $5.7266-6.2671$ & 6.3954 & 2.3726 & 0.0070 \\
\hline Mean preoperative sperm density (million/mL) & 2.1061 & $1.6329-2.7165$ & 3.0474 & 1.0449 & 0.0035 \\
\hline Mean preoperative sperm progressive motility (\%) & 1.6031 & $1.1037-2.3285$ & 0.4720 & 0.1904 & 0.0132 \\
\hline Total testosterone (ng/dL) & 0.9483 & $0.9067-0.9918$ & -0.05310 & 0.02287 & 0.0702 \\
\hline
\end{tabular}


Shabana et al.

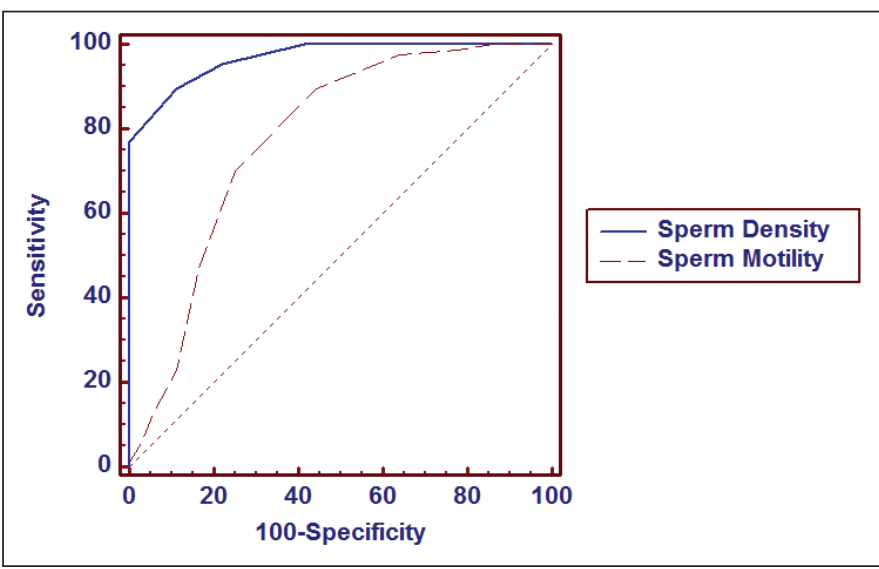

Fig. 1. Receiver operator characteristic curve analysis for significant variables.

These parameters showed significant predictive values in both univariate and multivariate analyses. Also, the preoperative sperm density and motility greatly affected the degree of post-varicocelectomy improvement, as such cases with sperm concentration and progressive motility of less than $8 \mathrm{million} / \mathrm{mL}$ and $18 \%$, respectively, had no significant improvement in subsequent semen analysis.

Our study has its limitations, including the relatively low number of selected cases and the absence of a power calculation. Therefore, higher cohort studies of open inclusion criteria are recommended to support our findings.

\section{Conclusion}

The grade of the varicocele, sperm density, and progressive motility are major predictors for the outcome of varicocelectomy. Cut-off values of $>8$ million $/ \mathrm{mL}$ and $>18 \%$ for sperm density and progressive motility in men with varicoceles of grade II or III indicate a successful outcome.

Competing interests: The authors all declare no competing financial or personal interests.

This paper has been peer-reviewed.

\section{References}

1. Dubin L, Amelar RD. Etiologic factors in 1294 consecutive cases of male infertility. Fertil Steril 1971;22:469-74.

2. Mallidis C, Czerwiec A, Filippi S, et al. Spermatogenic and sperm quality differences in an experimental model of metabolic syndrome and hypogonadal hypogonadism. Reproduction 2011;142:63-71. http:// dx.doi.org/10.1530/REP-10-0472

3. Wright EJ, Young GPH, Goldstein M. Reduction in testicular temperature after varicocelectomy in infertile men. Urology 1997;50:257-60. http://dx.doi.org/10.1016/S0090-4295(97)00191-X
4. Williams DH, Karpman E, Lipshultz LI. Varicocele: Surgical techniques in 2005. Can J Urol 2006;1:13-5.

5. Cayan S, Shavakhabov S, Kadioglu A. Treatment of palpable varicocele in infertile men: A meta-analysis to define the best technique. J Androl 2009;30:33-4. http://dx.doi.org/10.2164/jandrol.108.005967

6. Diegidio $P$, Jhaveri JK, Ghannam $S$, et al. Review of current varicocelectomy techniques and their outcomes. BJU 2011;108:1157-72. http://dx.doi.org/10.1111/i.1464-410X.2010.09959.x

7. Glassberg Kl, Poon SA, Gjertson CK, et al. Laparoscopic lymphatic sparing varicocelectomy in adolescents. J Urol 2008;180:326. hittp://dx.doi.org/10.1016/i.juro.2008.03.064

8. Cabrera SR, Torres RC, Larrea SJ, et al. Laparoscopic varicocelectomy in the adult patient. Arch Esp Urol 2008:61:815-3

9. Madgar I, Weissenberg R, Lunenfeld $B$, et al. Controlled trial of high spermatic vein ligation for varicocele in infertile men. Fertil Steril 1995;63:120-4.

10. Cayan S, Kadioglu TC, Tefekli A, et al. Comparison of results and complications of high ligation surgery and microsurgical high inguinal varicocelectomy in the treatment of varicocele. Urology 2000;55:750. http://dx.doi.org/10.1016/S0090-4295(99)00603-2

11. Jungwirth $A$, Gögüs $C$, Hauser $G$, et al. Clinical outcome of microsurgical subinguinal varicocelectomy in infertile men. Andrologia 2001;33:71. http://dx.doi.org/10.1046/j.1439-0272.2001.00407.x

12. Breznik R, Vlaisavljevic V, Borko E. Treatment of varicocele and male fertility. Arch Androl 1993;30:157. http://dx.doi.org/10.3109/01485019308987750

13. Krause W, Müller HH, Schäfer H, et al. Does treatment of varicocele improve male fertility? Results of the 'Deutsche Varikozelenstudie,' a multicentre study of 14 collaborating centres. Andrologia 2002;34:164. http://dx.doi.org/10.1046/i.1439-0272.2002.00494.x

14. Cayan $\mathrm{S}$, Erdemir F, Ozbey I, et al. Can varicocelectomy significantly change the way couples use assisted reproductive technologies? J Urol 2002;167:1749-52. http://dx.doi.org/10.1016/S0022$5347(05) 65192-0$

15. Baazeem A, Belzile E, Ciampi A, et al. Varicocele and male factor infertility treatment: A new meta-analysis and review of the role of varicocele repair. Eur Urol 2011;60:796-808. http://dx.doi.org/10.1016/i. eururo.2011.06.018

16. Ishikawa T, Fuijsawa M. Effect of age and grade on surgery for patients with varicocele. Urology 2005;65:768. http://dx.doi.org/10.1016/j.urology.2004.11.009

17. Zini A, Boman J, Jarvi K, et al. Varicocelectomy for infertile couples with advanced paternal age. Urology 2008;72:109. http://dx.doi.org/10.1016/i.urology.2008.02.029

18. Hsiao W, Rosoff JS, Pale JR, et al. Older age is associated with similar improvements in semen parameters and testosterone after subinguinal microsurgical varicocelectomy. J Urol 2011;185:620-5. http://dx.doi. org/10.1016/i.juro.2010.09.114

19. Choi WS, Kim TB, Paick JS, et al. Factors related to improvement or normalization of semen parameters after microsurgical subinguinal varicocelectomy. Korean J Urol 2009;50:39-45. http://dx.doi. org/10.4111/kju.2009.50.1.3

20. Handel LN, Shetty R, Sigman M. The relationship between varicoceles and obesity. J Urol 2006;176:2138. http://dx.doi.org/10.1016/i.juro.2006.07.023

21. Hammoud AO, Wilde N, Gibson M, et al. Male obesity and alteration in sperm parameters. Fertil Steril 2008;90:222-2. http://dx.doi.org/10.1016/i.fertnstert.2007.10.011

22. Pham KN, Sandlow JI. The effect of body mass index on the outcomes of varicocelectomy. J Urol 2012;187:219-21. http://dx.doi.org/10.1016/i.juro.2011.09.033

23. Kondo $\mathrm{Y}$, Ishikawa T, Yamaguchi $\mathrm{K}$, et al. Predictors of improved seminal characteristics by varicocele repair. Andrologia 2009;41:20-3. http://dx.doi.org/10.1111/j.1439-0272.2008.00882.x

24. Rodriguez M, Alescio L, Russell A, et al. Predictors of improved seminal parameters and fertility after varicocele repair in young adults. Andrologia 2009;41:277-81. http://dx.doi.org/10.1111/j.14390272.2009.00919.x

25. Steckel J, Dicker A, Goldstein M. Relationship between varicocele size and response to varicocelectomy. J Urol 1993; 149:769-71.

26. Jonathan D. Schiff JD, Li PS, et al. Correlation of ultrasound-measured venous size and reversal of flow with Valsalva with improvement in semen-analysis parameters after varicocelectomy. Fertil Steril 2006;86:250-2. http://dx.doi.org/10.1016/i.fertnstert.2005.12.038

27. Jarow J, Ogle S, Eskew LA. Seminal improvement following repair of ultrasound detected subclinical varicoceles. J Urol 1996;155:1287-90. http://dx.doi.org/10.1016/S0022-5347(01)66245-1

Correspondence: Dr. Waleed Shabana, Faculty of Medicine, Zagazig University, Egypt; waleed.shabana@gmail.com 